Rev. High Pressure Sci. Technol., Vol. 7 (1998) 1241 1243

\title{
The Influence of High Pressure in Palladium Catalyzed Coupling Reactions
}

\author{
Stephan Hillers, Anne Mengel, Kerstin Bodmann, and Oliver Reiser* \\ Institut für Organische Chemie der Universität Regensburg, Universitätsstr. 31, 93040 Regensburg, Germany
}

\begin{abstract}
The influence of high pressure (1-10 kbar) in solution on palladium catalyzed coupling reactions is examined both under the aspect of reactivity as well as selectivity. We present evidence that pressure can considerably accelerate such reactions as well as dramtically increase the turnover numbers of the catalysts. Moreover, new catalytic reactions become possible by using pressure: we present here our preliminary results on palladium catalyzed acylations of alkenes and the synthesis of trisubstituted alkenes by a new domino process combining the Horner-WadsworthEmmons and the Heck reaction.
\end{abstract}

[palladium, alkenes, $\alpha, \beta$-unsaturated ketones, Heck reaction, Horner-Wadsworth-Emmons reaction]

\section{Introduction}

Two of the big challenges in transition metal mediated reactions are to find more selective as well as more efficient catalysts in order to develop economical processes in organic synthesis. Besides designing new metal-ligand combinations for catalytic processes, it appears to be also of importance to investigate non traditional reaction conditions such as ultrasound, microwaves, or high pressure for catalysis.

We became interested in the area of high pressure catalysis during our attempts to develop a catalytic process to anti-aldol compounds 3 from readily available allyl alcohols 1 (Scheme 1): Rhodium-catalyzed hydroformylation of 1 under carefully controlled conditions and subsequent acid catalyzed elimination of water leads in a one pot procedure directly to substituted dihydrofurans 2 in moderate to good yields (35-70\%). Palladium-catalyzed arylation of $\mathbf{2}$ proceeds highly diastereoselectively to yield exclusively trans-disubstituted 2,3-dihydrofurans $4(48-67 \%)$, which gave rise to anti-aldol compounds 3 $(>90 \%)$ on subsequent oxidative cleavage by ozonolysis. [1]

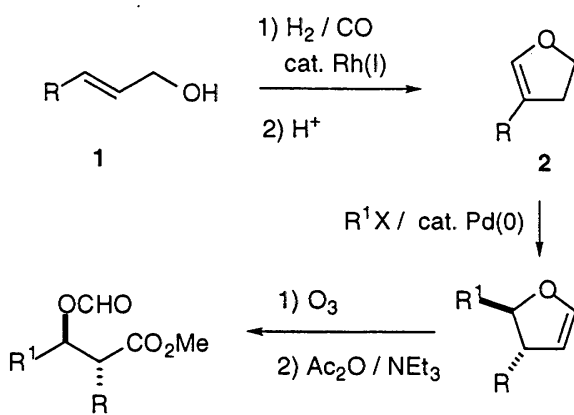

3

Scheme 1 .

The unsatisfactory step of this sequence has been the palladium catalyzed coupling of the dihydrofurans 2 , requiring long reaction times, high reaction temperatures, and high catalyst loading. Moreover, in difference to 2,3-dihydrofuran itself, only aryl iodides but not arly triflates would react with 2 , thus preventing so far the development of an asymmetric version of this particular reaction. We were therefore studying whether the application of high pressure (1-10 kbar) in liquid phases would improve on such palladium catalyzed coupling reactions.

\section{Results and Discussion}

There have been only very few studies investigating the influence of pressure in transition metal catalyzed reactions. [2] Due to the complexity of catalytic processes, which proceed usually not by a single step, it is difficult to predict the net effect of pressure. It has been suggested that incorporation such as oxidative addition and complexation of substrates to a metal are favored, extrusion such as reductive elimination and decomplexation are disfavored, and intramolecular processes such as insertion, migration and deinsertion should not be influenced by pressure. ${ }^{[3]}$

However, the situation appears to be more complicated: the most crucial point seems to be the question if ligand exchange remains possible under pressure ${ }^{[4]}$ so that a catalytic cycle can occur. There are two distinct mechanistic pathways by which ligand exchange reactions can take place. In electronically saturated metal complexes such as $\operatorname{Pd}(0) \mathrm{L}_{4}$ the dissociation of a ligand must occur first before a new ligand can coordinate (dissociative mechanism). The dissociation of a neutral ligand, being usually the rate determining step, should be hindered rendering the overall process unfavorable under pressure

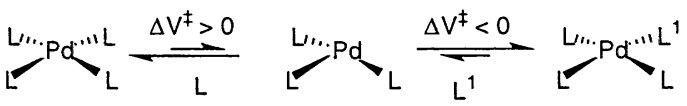

$$
\begin{aligned}
& \begin{array}{lll}
\mathrm{Pd}(0) & \mathrm{Pd}(0) & \mathrm{Pd}(0)
\end{array}
\end{aligned}
$$

However, dissociation of an ionic leaving group should be favored by pressure due to electrostriction. Moreover, in electronically unsaturated metal complexes such as $\mathrm{Pd}(\mathrm{II}) \mathrm{X}_{2} \mathrm{~L}_{2}$ the additional possibility of coordination of a ligand to the metal prior or simultaneously to the extrusion of another ligand exists (associative mechanism). If the rate determining step is the initial addition of the ligand, these processes should also be favored by pressure.

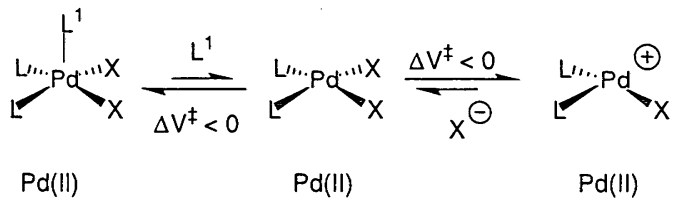

18 electrons

16 electrons

14 electrons 
The principles for ligand exchange should apply also to oxidative addition and insertion and vice versa to reductive elimination and deinsertion processes. To allow an oxidative addition or an insertion to take place, the substrate in question must first be able to associate with the metal center. Subsequently, the reorganization of the substrates in the coordination sphere of the metal leading to the oxidative addition or insertion should proceed without significant changes in volume and therefore be unaffected by pressure.

We have chosen for our investigation the coupling between unsubstituted cyclic alkenes $\mathbf{5}$ and iodobenzene (Scheme 2), a reaction well precedented in the literautre under various reaction conditions at normal pressure. ${ }^{[5]}$ Indeed, monitoring the reaction between 2,3-dihydrofuran (5a) and iodobenzene using a catalyst formed in situ from $\mathrm{Pd}(\mathrm{OAc})_{2} / \mathrm{PPh}_{3} 1: 2$ at pressures between 1 bar and 8 kbar clearly revealed its beneficial effect for the reaction rate $\left(\mathrm{k}_{\mathrm{rel}}(1 \mathrm{bar})=1 ; \mathrm{k}_{\mathrm{rel}}(2\right.$ $\left.\mathrm{kbar})=4 ; \mathrm{k}_{\mathrm{rel}}(4 \mathrm{kbar})=9 ; \mathrm{k}_{\mathrm{rel}}(8 \mathrm{kbar})=23\right) .{ }^{[6]}$ From these values, an activation volume of $\Delta \mathrm{V}^{\ddagger}=-12 \mathrm{~cm}^{3} / \mathrm{mol}$ was determined, which is significantly less than zero (i.e. rate acceleration) but not as negative as the activation for DielsAlder reactions $\left(\Delta \mathrm{V}^{\dagger}=-25\right.$ to $\left.-40 \mathrm{~cm}^{3} / \mathrm{mol}\right)$, the classical example for an accelerated reaction by pressure. It could not be determined which specific reaction steps were accelerated in the coupling of $5 \mathrm{a}$, but the kinetics suggest that the initial oxidative addition of palladium( 0 ) to iodobenzene is not the rate determining step under pressure.

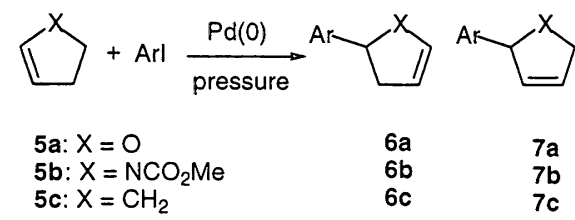

Scheme 2

Equally exciting was also the observation that the lifetime of the palladium catalyst is considerably prolonged in these coupling reactions: While at a reaction temperature of $60^{\circ} \mathrm{C}$ under normal pressure the turnover numbers were determined to be around $250-280$, at $8 \mathrm{kbar}$ under otherwise unchanged conditions TON's of up to 20000 could be reached with $\mathbf{5 a - b}$ and up to 100000 with $\mathbf{5 c}$ as the substrate. Improved turnover numbers were already found at $2 \mathrm{kbar}$, and also in the absence of any stabilizing phosphines. Increasing the reaction temperature to $100^{\circ} \mathrm{C}$ TON's above $100000(\mathbf{5 a}-\mathbf{b})$ and up to $770000(\mathbf{5 c})$ were found when the reaction was carried out at a pressure of 8 kbar. ${ }^{[7]}$

Moreover, it has been observed that the ratio of the regioisomers $6 \mathbf{a}$ to $7 \mathbf{a}$ is strongly dependent on pressure at high concentrations of triphenylphosphine ( $\left.\mathrm{Pd}: \mathrm{PPh}_{3}=1: 60\right): \mathbf{6 a}$ is the preferred product at normal pressure (6a:7a $90: 10)$, while a reversal in regioselectivity is observed at $10 \mathrm{kbar}$ (6a:7a 25:75). Apparently, the bimolecular ligand extrusion of $7 \mathbf{a}$ from $\pi$ complex 9 is accelerated by pressure compared to the unimolecular isomerization to 8 (Scheme 3 ) ${ }^{[8]}$ The same principle has been subsequently used to control the regioselectivity in palladium catalyzed [3+2] cycloadditions. ${ }^{[9]}$

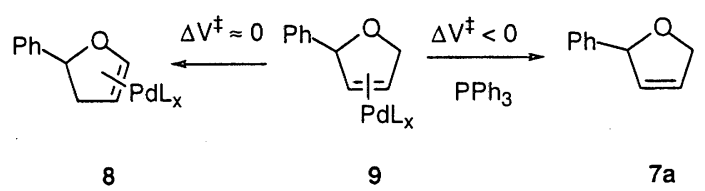

Scheme 3

Pressure also offers the possibility of the development of new catalytic reactions. While at normal pressure the palladium catalyzed, intermolecular coupling of acid chlorides with alkenes can only be accomplished using aroyl chlorides $(\mathrm{R}=$ $\mathrm{Ar})$ and vinyl ethers $(\mathrm{X}=\mathrm{OR}),{ }^{[10]}$ under high pressure a considerable broader range of acid chlorides and alkenes becomes available (Scheme 4).

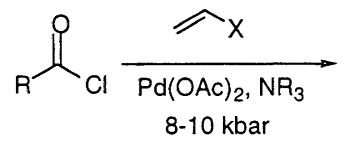

10<smiles>[X]/C=C/C([R])=O</smiles>

11
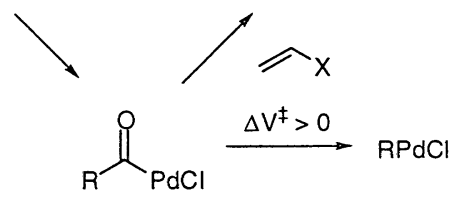

12

$\mathrm{R}=$ Aryl, Adamantyl, ${ }^{t} \mathrm{Bu}$
$\mathrm{X}=\mathrm{OR}, \mathrm{CO}_{2} \mathrm{R}, \mathrm{Ph}$

Scheme 4.

Our initial working hypothesis has been that after insertion of $\operatorname{Pd}(0)$ into the acid chloride 10 to give rise to 12 , the application of high pressure would prevent the $\mathrm{CO}$ extrusion to yield 13 but rather allow coupling with an alkene to give the $\alpha, \beta$-unsaturated ketone 11 . Indeed, at pressures above $7 \mathrm{kbar}$ exclusively 11 is obtained, while no coupling products arising from 13 were observed. [11] However, it was surprising to note that acylation would always occur at the $\beta$-position of the alkene. This was especially true using vinyl ethers, contrasting the outcome of a regular Heck-reaction with such substrates, e.g. the previously discussed coupling of $\mathbf{5 a}$ and iodobenzene. Moreover, electron rich alkenes are considerablly better substrates in this reaction than electron poor alkenes, which is also not the case in Heck reactions. Further doubt on the above mechanism was shed by the fact that if catalytic amounts of triphenylphosphine are present, which should facilitate the reduction of $\mathrm{Pd}(\mathrm{II})$ to $(\mathrm{Pd}) 0$ and furthermore stabilize $\mathrm{Pd}(0)$ complexes, the reaction does not take place at all. We, therefore, suggest that alternatively $\mathrm{Pd}(\mathrm{II})$ might act as a Lewis acid which in the combination with high pressure might 
activate the acid chloride sufficiently to undergo an electrophilic addition to the alkene. Further corroboration of this hypothesis is found in the fact that electron rich alkenes such as 2,3-dihydrofuran (5a) can be acylated with benzoyl chloride (14) at high pressure in the absence of a palladium catalyst to give $\mathbf{1 5}$ as the sole product (Scheme 5).

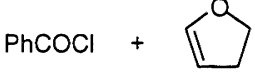

14

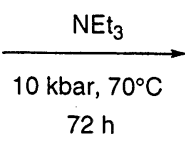

$55 \%$

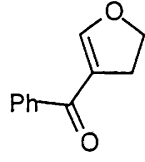

15
Scheme 5

Using pressure, milder and more economical reaction conditions can be used for certain reactions. E.g. the alkenylation of aldehydes with phosphonates (Horner-Wadsworth-Emmons (HWE) reaction) is readily accomplished at room temperature under pressure in the presence of just triethylamine (Scheme 6), while under normal pressure stronger bases or alternativley stochiometric amounts of a Lewis acis such as lithium chloride ${ }^{[12]}$ have to be employed. Aryl aldehydes are alkenylated particulary well under these conditions, while with alkyl aldehydes double bond isomerization gives rise to side products in some cases. In all cases a remarkable high $(E)$-selectivity was found, even if phophonates were used such as $\mathbf{1 7} \mathrm{b}^{[13]}$ which should yield predominantly (Z)-configurated products.<smiles>[2H]C=O</smiles>

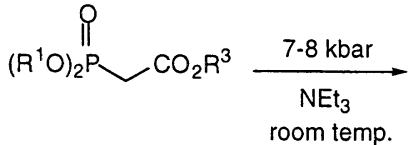

17a: $R^{1}=E t, R^{3}=M e$ 17b: $\mathrm{R}^{1}=\mathrm{CF}_{3} \mathrm{CH}_{2}, \mathrm{R}^{3}={ }^{i} \mathrm{Pr}$

$18(29-88 \%)$ oom temp.

16<smiles>[R]C=CC(=O)O</smiles>

$\mathrm{R}=\underset{\text { Aryl }}{\text { Alkyl, }}$

Scheme 6

Using this alkenylation protocol, a new domino process could be designed for the synthesis of trisubstituted alkenes $\mathbf{2 0}$ by combining a HWE and a Heck reaction (Scheme 7). Pressure proved to be beneficial not only for the alkenylation step but also for the subsequently following arylation via a Heck reaction, since disubstituted alkenes are generally considerably less reactive in such coupling reactions than monosubstituted ones. However, in the case of $R \neq A r$, mixtures of $(E) /(Z)$ isomers are formed, as was also noted in Heck reactions with cinnamic esters under normal pressure conditions. ${ }^{[14]}$

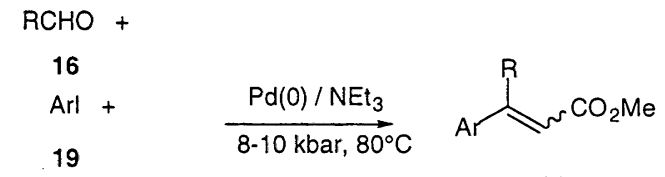

20

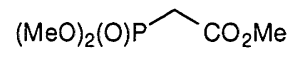

17

\begin{tabular}{|c|c|c|c|}
\hline$R$ & Ar & $\begin{array}{r}\text { yield } \\
{[\%]}\end{array}$ & $E / Z$ \\
\hline \multicolumn{2}{|c|}{$\mathrm{Ph}$} & 79 & \\
\hline \multicolumn{2}{|c|}{$p$-OMe-Ph } & 73 & \\
\hline$p$-OMe-Ph & $\mathrm{H}$ & 80 & $27: 73$ \\
\hline $\mathrm{H}$ & $p$-OMe-Ph & 90 & $70: 30$ \\
\hline $\mathrm{Me}$ & $\mathrm{Ph}$ & 56 & $>95:<5$ \\
\hline
\end{tabular}

Scheme 7.

In conclusion, we hope that we could demonstrate that pressure can be beneficial in palladium catalyzed reactions under various aspects.

Acknowledgment: This work was supported by the Volkswagenstiftung (AZ 68/870), the Deutsche Forschungsgemeinschaft (RE948-2 and Graduiertenkolleg Hochdruck, University of Göttingen), the Fonds der Chemischen Industrie, Hoechst AG, Bayer AG and Degussa AG. OR is indebted to the Winnacker foundation for a fellowship.

\section{References}

[1] S. Hillers, O. Reiser, Synlett, 153 (1995).

[2] Review: O. Reiser, Topics in Catalysis (1997), in press.

[3] T. Sugihara, M. Takebayashi, C. Kaneko, Tetrahedron Lett., 36, 5547 (1995).

[4] R. v. Eldik, T. Asano, W. J. 1. Noble, Chem. Rev., 89, 549 (1989).

[5] (a) R. C. Larock, W. H. Gong, J. Org. Chem., 55, 407 (1990). (b) R. C. Larock, W. H. Gong, J. Org. Chem., 54, 2047 (1989). (c) F. Ozawa, A. Kubo, Y. Matsumoto, T. Hayashi, E. Nishioka, K. Yanagi, K. Moriguchi, Organometallics, 12, 4188 (1993). (d) F. Ozawa, Y. Kobatake, T. Hayashi, Tetrahedron Lett, 34, 2505 (1993).

[6] S. Hillers, O. Reiser, J. Chem. Soc. Chem. Commun. 2197 (1996).

[7] S. Hillers, S. Saratori, O. Reiser, J. Am. Chem. Soc., 118, 2077 (1996).

[8] S. Hillers, O. Reiser, Tetrahedron Lett, 34, 5265 (1993).

[9] B. M. Trost, J. R. Parquette, A. L. Marquart, J. Am. Chem. Soc., 117, 3284-3285 (1995).

[10] C.-M. Andersson, A. Hallberg, J. Org. Chem., 53, 4257 (1988).

[11] cf. H.-U. Blaser, A. Spencer, J. Organomet. Chem., 233, 267 (1982).

[12] M. A. Blanchette, W. Choy, J. T. Davis, A. P. Essenfeld, S. Masamune, W. R. Roush, T. Sakai, Tetrahedron Lett., 25, 2183 (1984).

[13] W. C. Still, C. Gennari, Tetrahedron Lett., 24, 4405 (1983).

[14] M. Moreno-Manas, M. Perez, R. Pleixats, Tetrahedron Lett., 41, 7449 (1996). 